\title{
FEM Analysis and Experimental Research into Carrier Brackets in Ventilated Facades
}

\author{
Michał Kołaczkowski ${ }^{1 *}$, Aleksander Byrdy ${ }^{1}$ \\ ${ }^{1}$ Faculty of Civil Engineering, Cracow University of Technology, Warszawska 24, 31-155 Cracow, Poland \\ * Corresponding author, e-mail: mkolaczkowski@pk.edu.pl
}

Received: 04 February 2020, Accepted: 05 May 2020, Published online: XXXxxxxxxx 2020

\begin{abstract}
Ventilated facades are one of the most durable and attractive ways of finishing a building facade. The weight of cladding panels and substructure elements of ventilated facades is transferred into building structure via carrier brackets (mounting brackets). This article is focused on resistance to vertical load which is one of the basic technical requirements that need to be met by facades carrier brackets inside the European Union, defined in European Technical Approval Guidelines - ETAG 034. FEM models of carrier brackets were presented, and the results of a non-linear analysis were described. The results of the numerical analysis were verified by means of laboratory testing. The article examines the influence of adopting various material stress-strain diagrams in FEM models on calculation results, especially when pertaining to the viability of applying a diagram in accordance with the continuous strength method (CSM). Based on the laboratory tests and the analysis of the FEM models it was shown which part of the carrier bracket is its weakest link and is decisive for its load-bearing capacity. The relationship between serviceability limit state and ultimate limit state for stainless steel brackets with various overhangs was also presented.
\end{abstract}

Keywords

ventilated facade, carrier brackets, mounting brackets, FEM analysis, continuous strength method

\section{Introduction}

Ventilated facades are one of the most popular technologies of finishing exterior walls in civic buildings. Ventilated facades are popular due to high quality of their cladding materials which provide excellent visual properties of building facades. Materials such as fiber cement, HPL, magnesium composites, natural stone, ceramics etc. are used as external cladding. Cladding panels are mounted to the substructure which transfers the dead load and wind load onto the building's structure elements. The substructure of ventilated facades consists of a set of rails suspended on carrier brackets and supported by stabilizing brackets that transfer load generated by wind (see Fig. 1). Carrier brackets of ventilated facades transfer the weight of facade cladding and the substructure onto load-bearing parts of the building's walls. Additionally, carrier brackets can also transfer wind load (pressure and suction) which acts upon the surface of facade claddings. A typical material used for the production of carrier brackets is aluminum alloy 6060 T6 and 1.4301 stainless steel. Most brackets have a shape of an angled bracket and is used for single-sided mounting of vertical

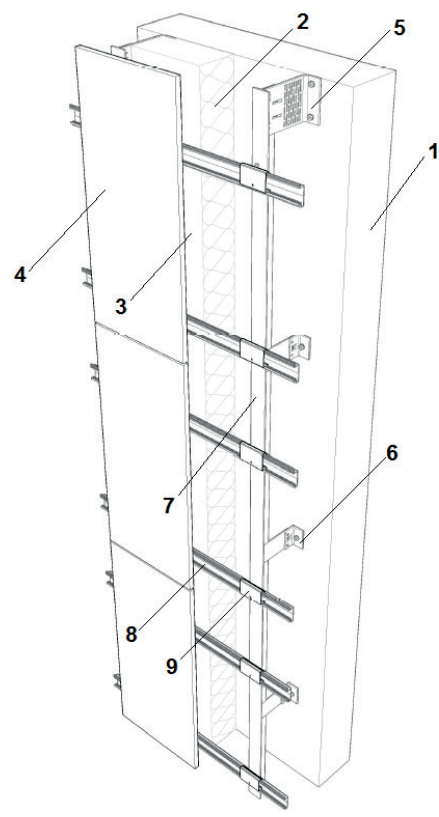

Fig. 1 Example ventilated facade with a heavy facade cladding: 1 - substrate (wall), 2 - thermal insulation, 3 - ventilating gap,

4 - cladding panel, 5 - carrier bracket, 6 - stabilizing bracket, 7 - vertical grid rail, 8 - horizontal grid rail, 9 - cladding mounting clasp 
rails in the facade's substructure. Due to the thickness of thermal insulation currently in use on building walls, the bracket's overhang is usually somewhere between $130 \mathrm{~mm}$ and $230 \mathrm{~mm}$. Aluminum brackets are manufactured by extrusion and steel brackets are usually manufactured by bending or cold stamping of sheet metal. Examples of carrier bracket solutions are presented in Fig. 2.

\section{Technical requirements for ventilated facade mounting}

Mounting brackets for ventilated facade are the basic and the most responsible element that transfers load from the facade onto the building's structure. A carrier bracket acts as a joint mount of a vertical rail in the form of a support anchored in the tie beam. The main loads transferred through carrier brackets are dead load (cladding and substructure), as well as wind load. Additionally, one has to take into consideration thermal loads and possible live load or accidental load according to EN 1991-1-1:2002 [1]. The most important live loads are crowd pressure and local soft body or hard body impact according to ISO 7892:1988 [2]. When delivering objects localized in territories prone to earthquake, it is required to design facades that are impervious to seismic influence which can be qualified as an accidental load [3]. When it comes to systemic grid structure solutions, each mounting element should undergo test procedures pursuant to the regulations of the European Technical Assessment Group ETAG 034 [4]. According to ETAG 034 [4], "if calculation according to relevant standards is not possible, the load bearing capacity and deformation under loading (tension and shear) shall be determined by test. (...) The aim of the test is to determine the load bearing capacity and wind resistance of the brackets and their fixings to the subframe under tension and shear loads". In ETAG 034 [4], no guidelines pertaining to carrying out computer calculations were given. Instead, laboratory testing procedures were presented. Research procedures described in ETAG 034 [4],

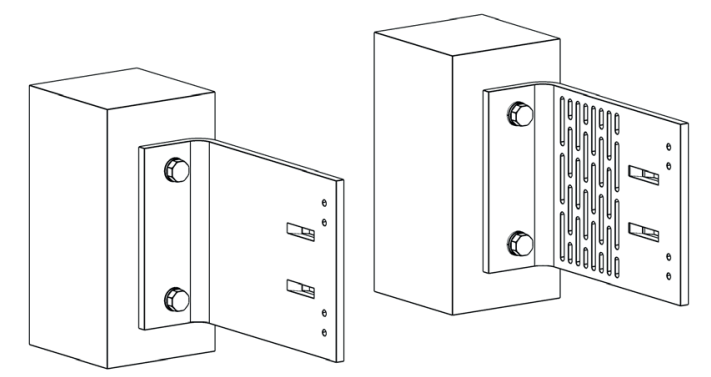

Fig. 2 Examples of carrier brackets: traditional aluminum or stainlesssteel bracket (left), insulating bracket made of perforated stainlesssteel (right) each time recommends performing at least 5 experiments that verify the load-bearing capacity of loaded brackets, depending on their application. For carrier brackets, an examination under a vertical (parallel to their plane of mounting) load was assigned (see Fig. 3), which is a model of loading brackets with the dead load exerted by the elements of the ventilated facade.

Another examination applicable to carrier brackets and stabilizing brackets are load-bearing tests of brackets subject to horizontal (perpendicular to their plane of mounting) load. In both research regiments, it is acceptable to examine symmetrical and asymmetrical (one-sided) brackets, but it is recommended to place bracket mounting bolts in ovalshaped holes, in a position that is most distant from the load axis. In ETAG 034 [4], an examination is described where a carrier bracket is to be subjected to a series of cyclical loads with the load in traction growing by $10 \mathrm{daN}$ each cycle, with constant speed of load below $500 \mathrm{daN} /$ minute.

For carrier brackets, it is important to determine the values of vertical loads, for which the following criteria are to be met:

- "1st criterion: The load Fr is that at for which the bracket acquires a residual distortion measured at the head of wing, equal to: $\Delta l=0.2 L x / 100$, where: $L x$ - being the length of the wing." (see ' $L$ ' in Fig. 4)

- "2nd criterion: The loads F1d and F3d are those which correspond to $1 \mathrm{~mm}$ and $3 \mathrm{~mm}$ displacement."

- "3rd criterion: The load Fs is that which corresponds to the failure."

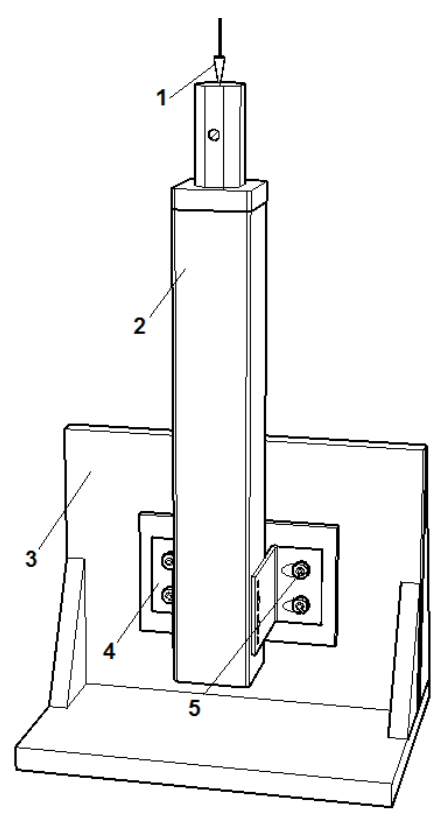

Fig. 3 Plan of a test bench for vertical loads in accordance with [4]: 1 - load (F), 2 - profile, 3 - substrate, 4 - bracket, 5 - fixing 
One can conclude that criterion 1 is equivalent to achieving ultimate limit state, whereas criterion 2 is equivalent to serviceability limit state, determined depending on the cladding technology requirements. In this article, a deflection of $3 \mathrm{~mm}$ - one that is typically used for claddings has been assumed as limit.

\section{Analyzed carrier brackets, FEM models and laboratory tests}

This article focuses on resistance to vertical load of brackets and design using FEM modelling. To this end, the finite element analysis of the carrier brackets was made, and laboratory tests was carried out to verify the results of the analysis. Using the developed FEM models, it was checked which part of the carrier bracket is its weakest link and is decisive for its load-bearing capacity and what is the relationship between serviceability limit state and ultimate limit state pursuant to EN 1993-1-4 [5] for carrier brackets made of stainless steel of various overhangs. It was also decided to examine the influence of adopting various material stress-strain diagrams in FEM analysis on calculation results, and in particular a diagram in accordance with continuous strength method (CSM) proposed by Garnder [6] and Afshan and Gardner [7].

The research was carried out on carrier brackets made of 1.4301 stainless steel in the shape of a cold-formed angled bracket made out of a steel sheet $4 \mathrm{~mm}$ in thickness. In order to meet the increased thermal insulation standards of thermal ventilated facades described by Nowak and Byrdy [8] and Bikasvet al. [9] brackets of lowered thermal conductivity parameters were designed, which was achieved by perforating the bracket's cantilever plate. Technical solutions of a thermal carrier bracket that was subject to tests is presented in Fig. 4.

Mounting of brackets to a rigid substrate by means of M10 bolts was assumed in the least favorable distribution (Fig. 5). A FEM analysis was carried out for a model of a steel carrier bracket type A (with an overhang of $180 \mathrm{~mm}$ ) and laboratory tests performed in order to verify the modeling method were also carried out. The analyzed case pertained to a vertical load of a carrier bracket, which stems from the weight of cladding and substructure.

Subsequently, a comparative FEM analysis was carried out for three types of carrier brackets of varying overhangs. The calculations were performed for a basic (type A) carrier bracket, one with a lower overhang (type B) and one with a higher overhang (type C).
The FEM analysis was carried out using Dlubal RFEM 5.0 software. The elasto-plastic isotropic material model was adopted with three variants of stress strain diagrams. An analysis of large displacements was performed.

Before modeling commenced, a test of 1.4301 steel stretching was carried out and, as a result, a diagram of stress-strain relationship was acquired (Fig. 6).

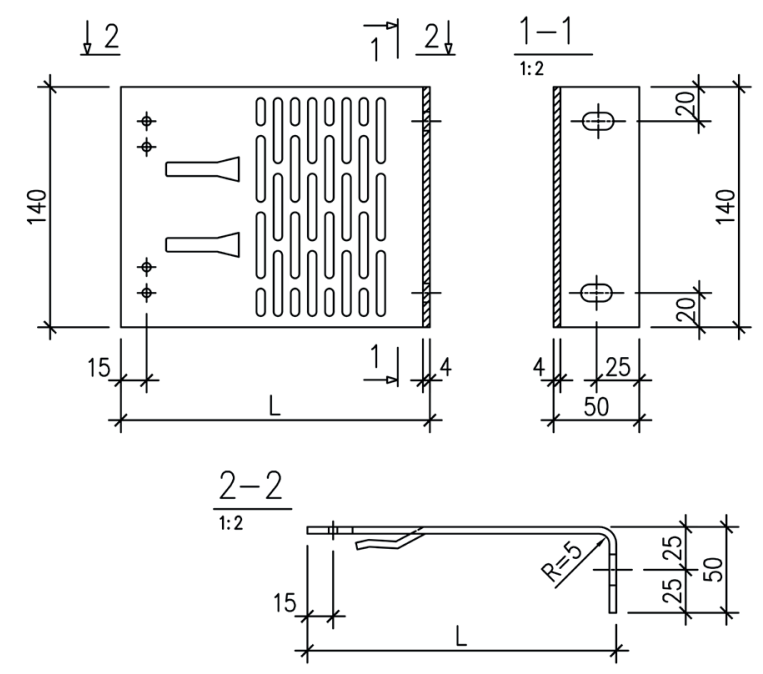

Fig. 4 Dimensions of a carrier bracket selected for durability testing

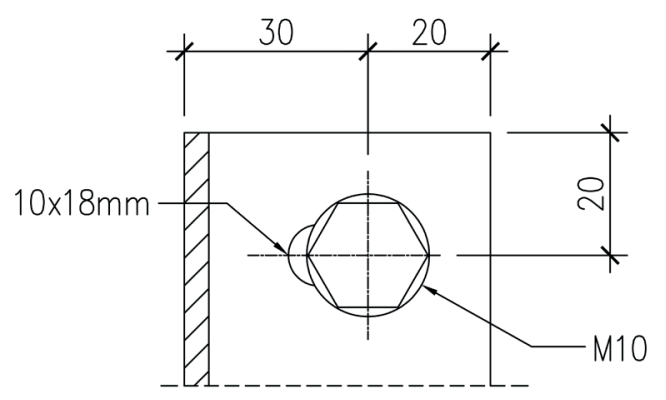

Fig. 5 Bolt layout inside an oval-shaped hole used in laboratory tests and assumed for FEM analysis

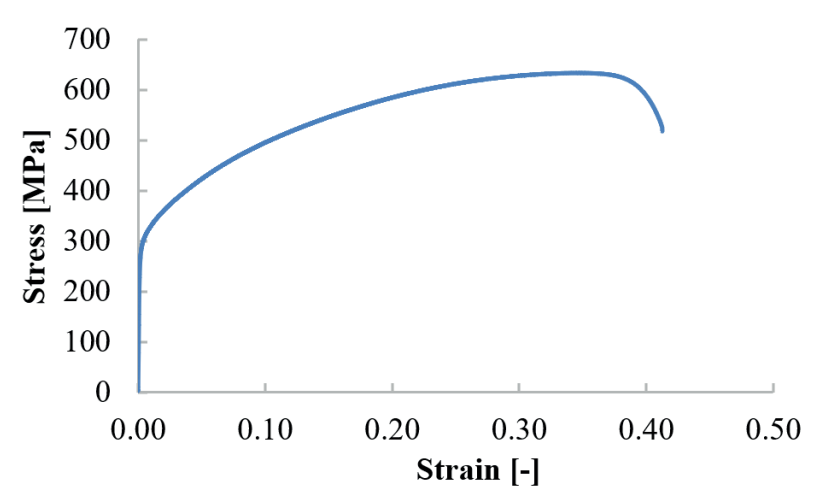

Fig. 6 An average diagram of stress-strain relationship acquired based on 1.4301 steel samples tests 
A bilinear diagram with strain hardening was also calculated using the continuous strength method (CSM) according to Gardner [6] and Afshan and Gardner [7]. As a comparison, a bilinear diagram with a yielding plateau - without strain hardening, according to EN 19931-1 [10] was assumed. The three variants of the stressstrain relationship described above used in the analysis are presented together in Fig. 7. The overview of the basic type A bracket model as compared to the testing bench is presented in Fig. 8. In FEM models, 4-node shell elements of
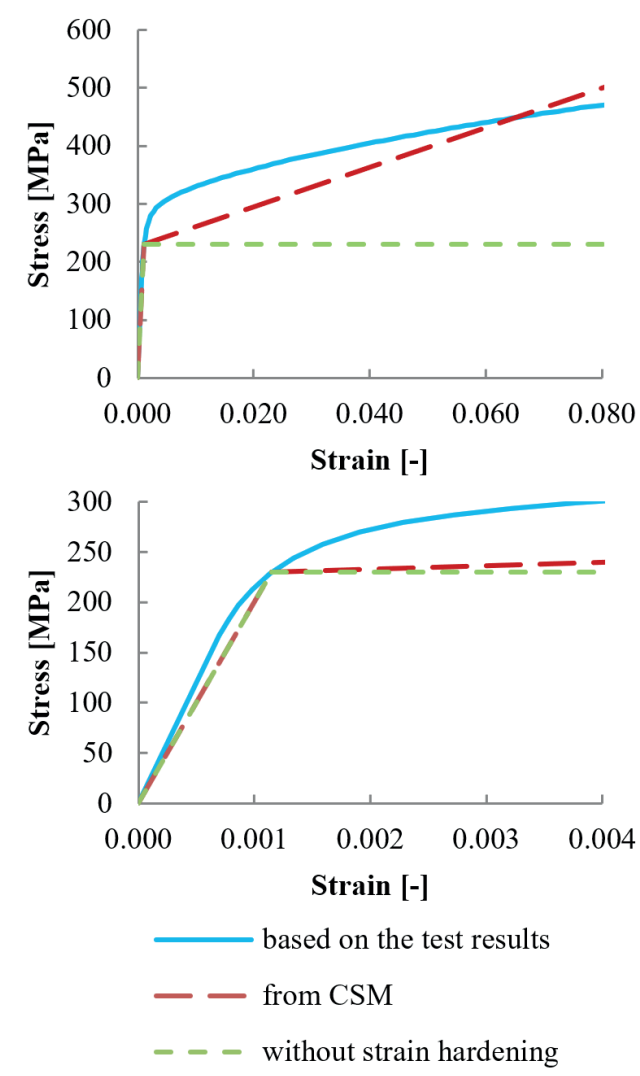

Fig. 7 Stress-strain relationships for 1.4301 stainless steel (top: range taken into account in the analysis; bottom: zoom in on the beginning of the chart)

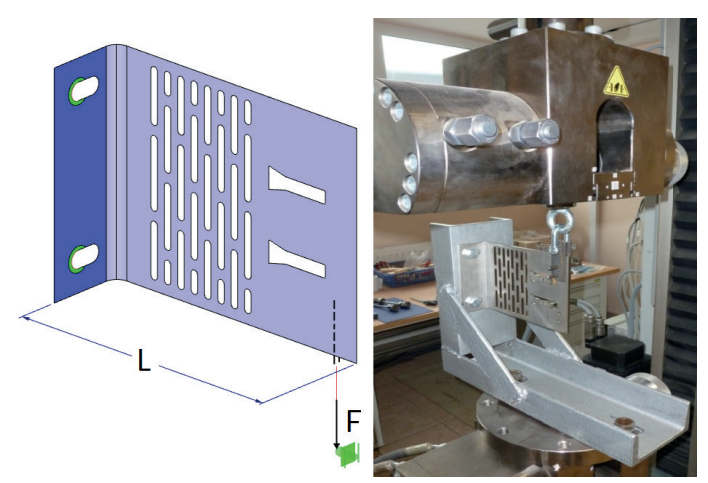

Fig. 8 FEM model of a carrier bracket (left), laboratory testing bench with upside down carrier bracket (right); L - bracket overhang, F - load maximum sizes between $0.5 \mathrm{~mm}$ (around anchor holes) and $5 \mathrm{~mm}$ were used. Displacement boundary conditions were assumed. The location of the supports is shown in Fig. 9, followed by descriptions of the types of supports used.

A one-way horizontal support (only contact pressure, no contact tension, friction omitted) orientated perpendicularly to the load-bearing wall within the area of the bracket's back wall was assumed - marked in blue in Fig. 9. Instead of modeling the bolt, displacement restrictions in appropriate directions were used. A two-way support around the holes was also assumed in the same direction (within the area of an exterior diameter equal to a diameter of a circle circumscribed on the head of the anchor and the interior diameter equal to the diameter of the hole) marked in green in Fig. 9.

A one-way linear support was adopted within the section where a steel sheet comes into contact with the bolt's shank (only contact pressure onto the bolt's shank, no contact tension, friction omitted) - marked in red in Fig. 9.

Vertical load was assumed for the regiment equivalent to the load applied during a laboratory test, using an articulated joint of $50 \mathrm{~mm}$ in length (Fig. 8). The loads were applied in maximum $0.2 \mathrm{kN}$ increments.

Laboratory testing was carried out on 5 samples of type A carrier bracket. A Z1200 Zwick/Roell press was used for testing. During testing, a load-displacement relationship was registered in the point where load was applied. The load was applied in the negative regiment, that is upside down in relation to the actual work and the developed FEM model (see Fig. 8). The testing bench had the rigidity that was significantly higher than the rigidity of the bracket being tested. The tests were carried out under displacement control at the speed of $5 \mathrm{kN} / \mathrm{min}$.

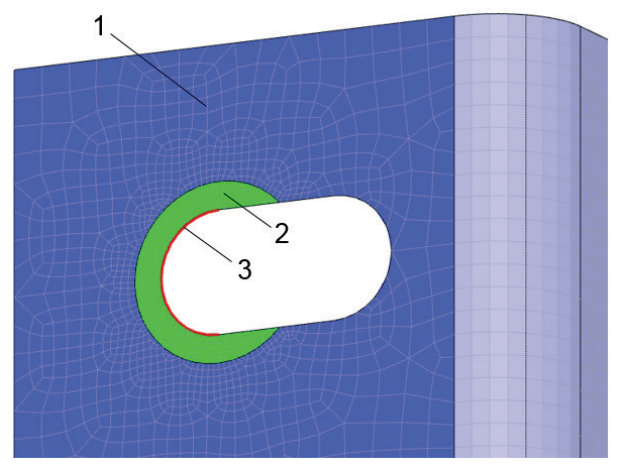

Fig. 9 Supports of the carrier bracket FEM model (the same supports were made around the bottom hole): 1 - one-way surface support - only contact pressure (blue), 2 - two-way surface support - contact pressure and tension (green), 3 - one-way linear support - only contact pressure on bolt's shank (red) 


\section{Results}

\subsection{A comparison of laboratory test results with the} results obtained from type A bracket FEM models

Fig. 10 shows load-displacement paths obtained in five trials during laboratory tests and an average diagram (displacement in the point of force application).

Fig. 11 presents an average diagram of load-displacement from laboratory tests as compared to type A bracket FEM analysis results, when using various stress-strain relationships. Averaged test results, together with results from FEM models are juxtaposed in Table 1. The form of failure observed during the course of tests is shown in Fig. 12. Bracket failure took place at $8.9 \mathrm{kN}$ of force.

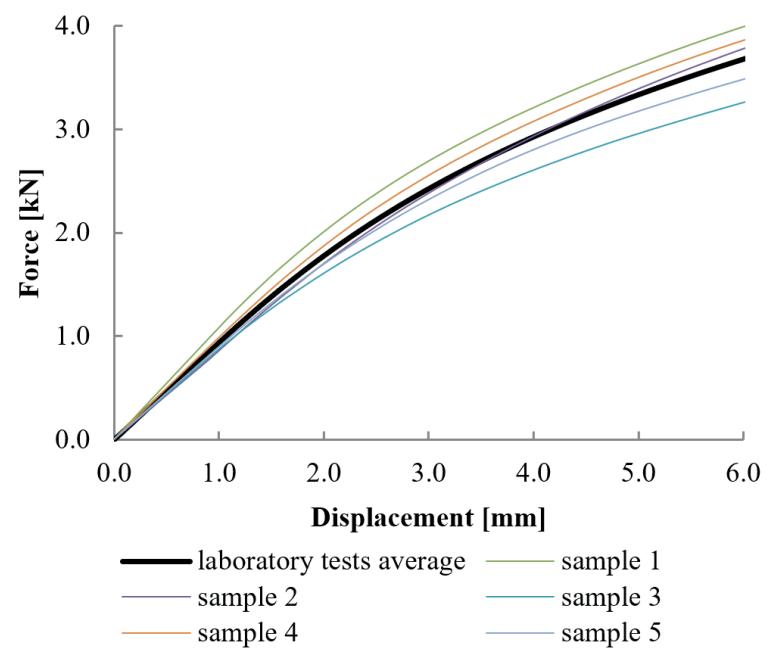

Fig. 10 Laboratory test results of a type A bracket in the form of loaddisplacement paths

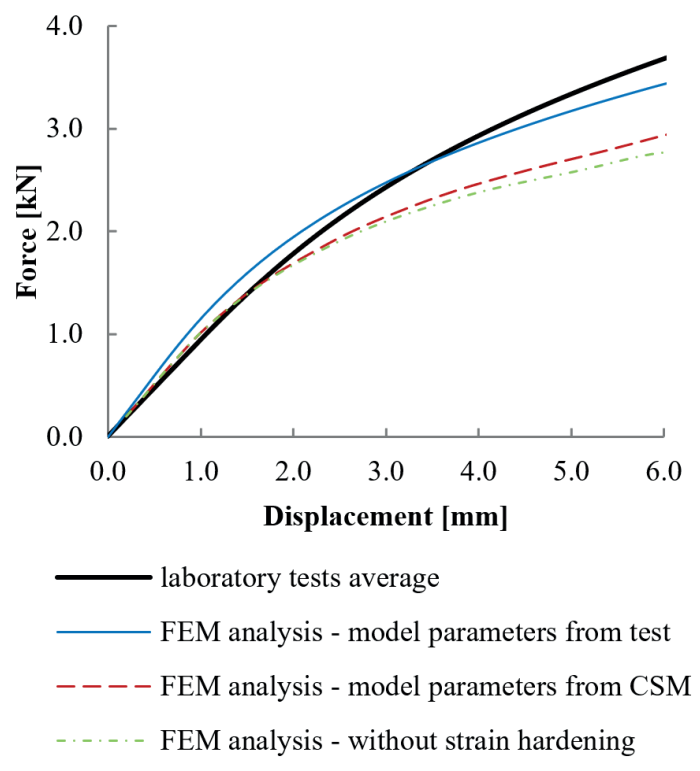

Fig. 11 Calculation results in the form of load-displacement paths for type A bracket juxtaposed with an averaged diagram from laboratory tests
Table 1 Type A bracket laboratory test results as compared to the results of FEM analysis for various material stress-strain diagrams

\begin{tabular}{lcc} 
& \multicolumn{2}{c}{ Force $(\mathrm{F})$ characteristic value $[\mathrm{kN}]$} \\
Test type & $\begin{array}{c}1 \mathrm{~mm} \\
\text { bracket deflection }\end{array}$ & $\begin{array}{c}3 \mathrm{~mm} \\
\text { bracket deflection }\end{array}$ \\
\hline $\begin{array}{l}\text { Laboratory tests: } \\
5 \text { bracket tests average }\end{array}$ & 0.94 & 2.42 \\
$\begin{array}{l}\text { FEM analysis: } \\
\text { parameters from tests }\end{array}$ & 1.14 & 2.47 \\
$\begin{array}{l}\text { FEM analysis: } \\
\text { parameters from CSM }\end{array}$ & 1.02 & 2.14 \\
$\begin{array}{l}\text { FEM analysis: } \\
\text { without strain hardening }\end{array}$ & 1.02 & 2.09 \\
\hline
\end{tabular}
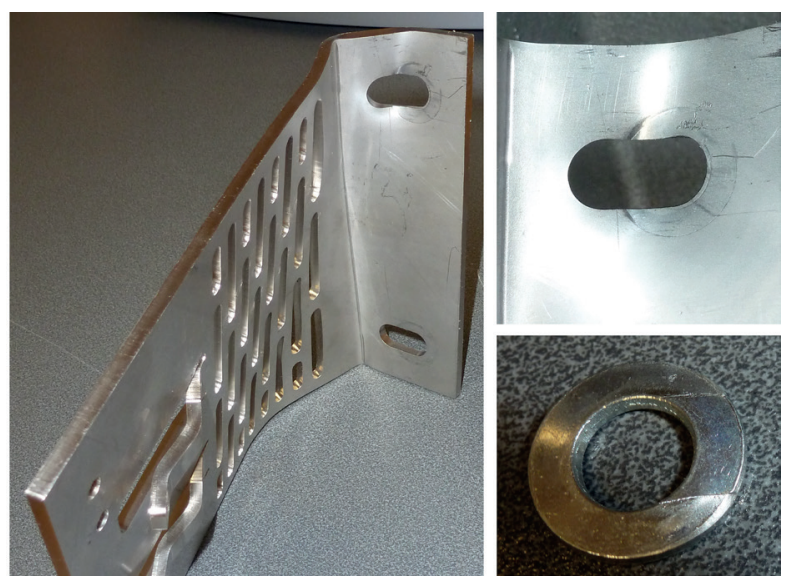

Fig. 12 Form of the bracket failure under destructive load of $8.9 \mathrm{kN}$ : general view of the bracket after the test (left), plasticized bracket mounting zone (top right), plasticized washer (bottom right)

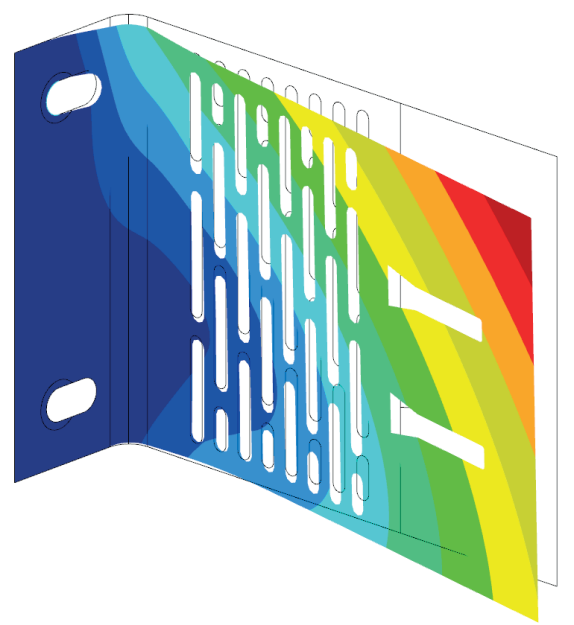

Fig. 13 The form of type A bracket deformation based on the FEM model under the vertical load of $8.9 \mathrm{kN}$

Fig. 13 depicts the deformation form of a type A bracket obtained by means of the FEM analysis using elasto-plastic isotropic material with the stress-strain diagram given from test (Fig. 6). 


\subsection{Comparative analysis of three bracket types with} varying overhangs (type $A, B$ and $C$ ) based on FEM models

Comparative analysis was carried out using a FEM models based on an elasto-plastic material with the stress-strain diagram from CSM. Fig. 14 presents load-displacement diagrams for the three types of brackets being analyzed. In order to perform a comparative analysis, the calculation results for laboratory tested brackets (type A bracket) with bracket of the lowest (type $\mathrm{B}$ bracket) and the highest practically utilized overhang (type $\mathrm{C}$ bracket) were juxtaposed in Table 2. The bracket analyses were carried out with the assumption all brackets were made of the same material, same cross section thickness and with the same shape of the mounting zone but with varied overhang. Table 2 juxtaposes the values for the load causing the deflection of the bracket's tip of $1 \mathrm{~mm}$ and $3 \mathrm{~mm}$ and the load values causing a $5 \%$ strain, which was assumed as a maximum that meets ULS, as is acceptable by EN 199314 [5] for detailed analyses by means of a finite element method. In order to facilitate comparison of results, the values of characteristic and design loads are given. The relationship between design and characteristic load equals $\gamma_{f}=1.35$ according to EN 1990 [11] for dead load. The maximum equivalent Huber-Mises strain value occurring on the external or internal side of the surface was checked, with the strain on one side of the surface calculated according to the Eq. (1), where $\varepsilon_{x}$ is strain in the direction of the axis $\mathrm{x}, \varepsilon_{y}$ is strain in the direction of the axis $\mathrm{y}, \gamma_{x y}$ is related rotation and $v$ is Poisson's ratio [12].

$$
\varepsilon=\frac{\sqrt{\left(\varepsilon_{x}-\varepsilon_{y}\right)^{2}+\left(\frac{\varepsilon_{x}+v \cdot \varepsilon_{y}}{1-v}\right)^{2}+\left(\frac{v \cdot \varepsilon_{x}+\varepsilon_{y}}{1-v}\right)^{2}+\frac{3}{2} \gamma_{x y}^{2}}}{\sqrt{2} \cdot(1+v)}
$$

Fig. 15 shows equivalent Huber-Mises strain maps around the top anchor hole for all three types of brackets.

\subsection{Comparison of FEM analyses of brackets with the use of various stress-strain diagrams and the influence of adopting various ULS criteria}

The comparison was carried out based on type B bracket with the overhang of $130 \mathrm{~mm}$ as, in this bracket, within the range of acceptable deflections, significant areas of steel plasticization were observed (Fig. 15). Fig. 16 presents load-displacement diagrams when using the material model with parameters from CSM and from diagram without strain hardening (see Fig. 7).

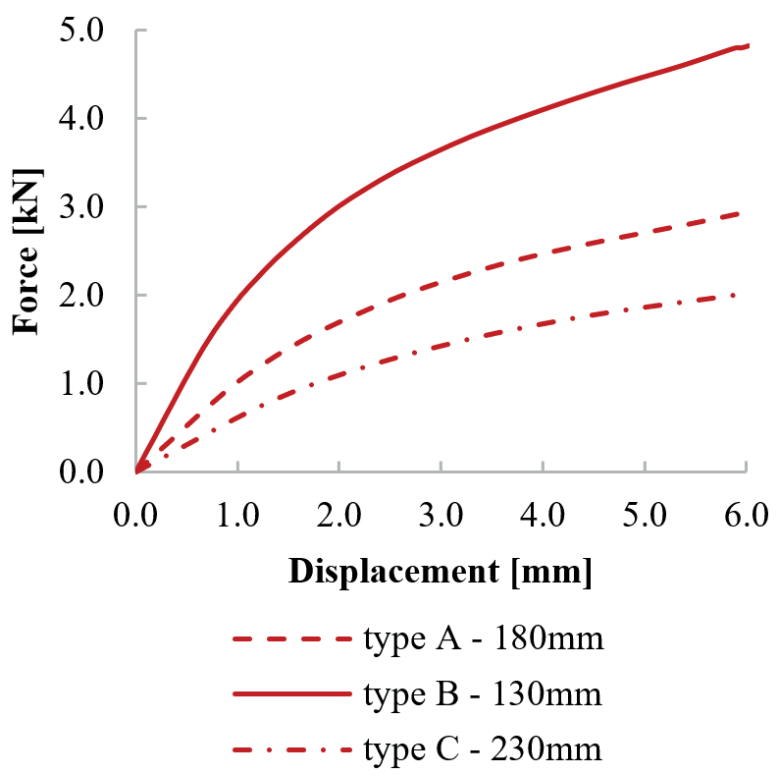

Fig. 14 FEM analysis results in the form of load-displacement paths for type A, B and C brackets (CSM material model)

Table 2 The results of the FEM analysis for type A, B and C brackets (parameters from CSM, $\gamma_{f}=1.35$ )

\begin{tabular}{lccc}
\hline Bracket type & \multicolumn{2}{c}{ Force $(\mathrm{F})$ characteristic / design value $[\mathrm{kN}]$} \\
& $\begin{array}{c}1 \mathrm{~mm} \text { bracket } \\
\text { deflection }\end{array}$ & $\begin{array}{c}3 \mathrm{~mm} \text { bracket } \\
\text { deflection }\end{array}$ & $\begin{array}{c}5 \% \text { equivalent } \\
\text { strain }\end{array}$ \\
\hline $\mathrm{A}, \mathrm{L}=180 \mathrm{~mm}$ & $1.02 / 1.38$ & $2.14 / 2.90$ & $2.11 / 2.85$ \\
$\mathrm{~B}, \mathrm{~L}=130 \mathrm{~mm}$ & $1.95 / 2.63$ & $3.65 / 4.92$ & $3.04 / 4.10$ \\
$\mathrm{C}, \mathrm{L}=230 \mathrm{~mm}$ & $0.62 / 0.83$ & $1.43 / 1.92$ & $1.63 / 2.20$ \\
\hline
\end{tabular}

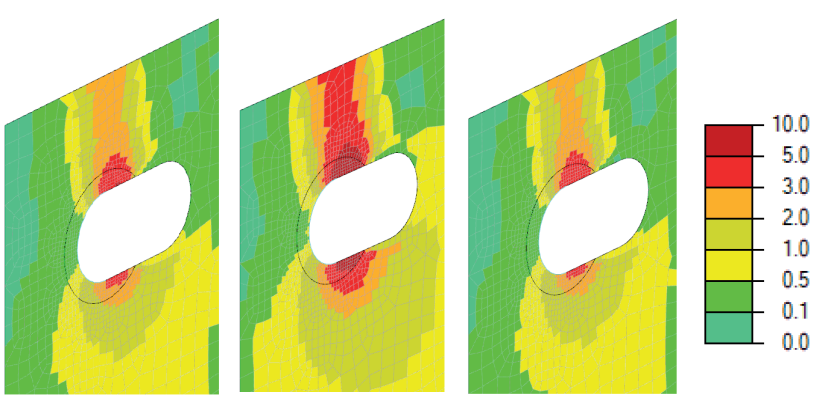

Fig. 15 Equivalent Huber-Mises strain in the zone around the top hole taking place at design load corresponding to characteristic load which causes a $3 \mathrm{~mm}$ bracket tip deflection (parameters from CSM, $\gamma_{f}=1.35$ )

In the diagrams, the values of force generating a $5 \%$ strain were marked and - for comparison - of one generating a strain of $0.2 \%$. Table 3 juxtaposes values of a limit load for SLS and ULS for a bracket being investigated. Fig. 17 presents the comparison of strains occurring at the same load when using two different stress-strain diagrams. 


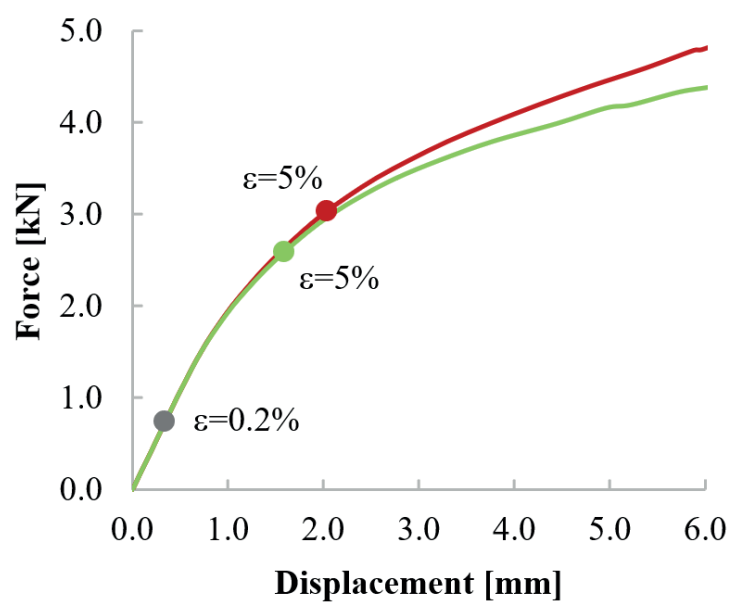

— from CSM

without strain hardening

Fig. 16 FEM analysis results in the form of load-displacement paths for type B brackets when using different stress-strain assumptions

Table 3 Type B bracket FEM analysis results when applying various stress-strain diagrams

\begin{tabular}{lccc}
\hline $\begin{array}{l}\text { Material model } \\
\text { stressstrain } \\
\text { diagram type }\end{array}$ & $\begin{array}{c}\text { Force }(\mathrm{F}) \text { characteristic / design value }[\mathrm{kN}] \\
\text { deflection }\end{array}$ & $\begin{array}{c}0.2 \% \text { equivalent } \\
\text { strain }\end{array}$ & $\begin{array}{c}5 \% \text { equivalent } \\
\text { strain }\end{array}$ \\
\hline from CSM & $3.65 / 4.92$ & $0.74 / 1.00$ & $3.04 / 4.10$ \\
$\begin{array}{l}\text { without strain } \\
\text { hardening }\end{array}$ & $3.50 / 4.73$ & $0.74 / 1.00$ & $2.59 / 3.50$ \\
\hline
\end{tabular}
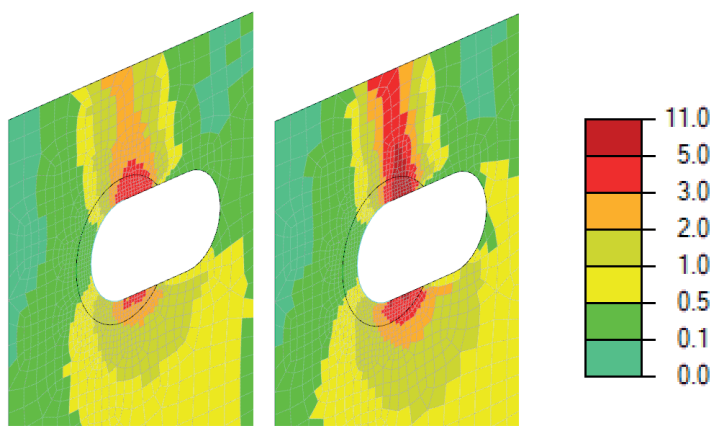

Fig. 17 Equivalent Huber-Mises strain in the zone around the top hole of type B bracket, occurring at a design load of $4.1 \mathrm{kN}$ when applying different stress-strain diagrams: from CSM (left), without strain hardening (right)

\section{Discussion}

Based on the analysis of diagrams in Fig. 11, a satisfactory compliance of the results obtained from FEM models with the results of laboratory tests was found. This confirms the usefulness of the adopted FEM model for analyzing the statics of steel brackets. The calculation results were evaluated using Root Mean Square Error (RMSE). The error analysis was carried out for the range shown in Fig. 11 - the range of displacement up to $6 \mathrm{~mm}$. The values of forces corresponding to displacements from the considered range were compared. The highest compliance of the FEM analysis results with the results of laboratory tests of the brackets was obtained for the model using material stress-strain diagram based on the stretch tests of the samples of the material used for bracket manufacturing - the RMSE was $0.15 \mathrm{kN}$. However, the CSM model might prove more useful for engineering analyses in practice due to the lack of technical capabilities to test samples of stainless steel used for a specific implementation. The RMSE for result diagram obtained for the model using CSM reached the value of $0.40 \mathrm{kN}$. The use of conservative material model without strain hardening resulted in RMSE value equal to $0.49 \mathrm{kN}$.

Both in bracket FEM models and in the laboratory tested brackets, with a relatively small strain in the cantilever part, a significant deformation of the mounting zone was observed. During laboratory tests, the mounting bolt washer has also been plasticized as a result of the mounting area deformation. Based on test results, it was determined that the cause of the bracket reaching a limit state of load-bearing capacity was the plasticization of the bracket mounting zone in the proximity of the oval-shaped hole (see Fig. 12). A limit state for load-bearing capacity was assumed to be the moment of reaching $5 \%$ strain which is acceptable in accordance with EN 1993-1-4 [5] for a detailed FEM analysis. This assumption was made taking into consideration the characteristics of stainless steel and the analyses presented in the literature $[13,14]$.

A comparative analysis of three brackets of varying overhangs (type A, B and C) made it possible to observe the relationship between loads that generated a limit deflection (SLS), and loads generating a limit strain (ULS). For the purpose of this analysis, a CSM stress-strain diagram was assumed, as it constitutes a better approximation of the realistic material stress-strain relationship in reference to a bilinear diagram without strain hardening within the range of the most significant strain, i.e. between $0.2 \%$ to $5 \%$ (see Fig. 7 ). As a limit SLS value, a deflection of the bracket's tip of $3 \mathrm{~mm}$ was assumed. In the case of $\mathrm{C}$ brackets, this condition was met before ULS was reached in the form of $5 \%$ strain. The opposite situation occurred in the case of B bracket where ULS was reached in the zone around an anchor hole with a load lower for about $14 \%$ than SLS (see Table 2). 
Fig. 15 shows that in the case of a type A bracket, with a load generating a deflection of $3 \mathrm{~mm}$, strains at the support just slightly exceeded the limit, but in the case of the most flexible type $\mathrm{C}$ bracket, the strains turned out to be significantly below limit, and for the relatively stocky type B bracket, a conspicuous exceeding of the allowable strains took place. In order to justify the assumptions made for the purpose of the above analysis, the comparison of analyses results for bracket models with the use of various stressstrain diagrams and the influence of assuming various ULS criteria was carried out. The diagrams presented in Fig. 16 clearly show that a strain of $0.2 \%$ took place at a relatively low load and during a very early phase of bracket deflection. Assuming a $0.2 \%$ strain as limit for ULS is extremely conservative and - in the authors' opinion - unjustified for carrier brackets. For that reason, in the performed analyses, reaching a strain of $5 \%$ is to constitute ULS. Table 3 Presents a significant difference between limit loads that meet the ULS from the model based on CSM in relation to the model using traditional diagram without strain hardening. In the case of a stocky type B bracket, the application of the CSM, which constitutes a better approximation of the actual material stress-strain relationship within the range of relevant stress values allows one to assume a load by $17 \%$ higher than when assuming the traditional bilinear diagram. A significant difference in strains with the same load and with different assumptions about the stress-strain diagram can be seen in Fig. 17. Within the range of acceptable displacements, the difference in meeting SLS are less relevant and are about $4 \%$.

\section{Conclusions}

It is a designer's decision to determine the maximum acceptable force the application of which will not exceed ultimate limit state and serviceability limit state of the carrier bracket. Due to the individual character of each implementation of the facade cladding it may turn out that the range of carrier brackets tested by the manufacturer is insufficient - in this case, FEM analysis can be performed.

Based on the analysis presented in the article, following conclusions can be formulated.

The carried out analysis proved that the proposed FEM modeling method is useful for engineering design which is confirmed by satisfactory compliance between the results obtained by means of the FEM analysis with the average results of the load-displacement relationship obtained by means of laboratory tests.

Based on the performed research, it was observed that, for the considered asymmetrical brackets made of a cold-formed angled bracket, the zone that has the biggest influence on their load-bearing capacity is the area around a bolt hole which becomes plasticized first. It can be determined that non-symmetrical bracket solutions made of a cold-formed angled bracket are not economical. Due to a low rigidity of the support zone, the brackets are subject to local deformations in that zone, while not taking advantage of the cantilever part material. As a result, in order to lower material investments when producing elements, different bracket solutions - such as designing brackets of variable wall thickness (made of thicker sheets in the support section and thinner in the cantilever section) - should be explored.

In the FEM analysis of the carrier brackets made of stainless steel it is recommended to assume $5 \%$ strain as a limit for ULS in accordance to EN 1993-1-4 [5]. In this case, the use of a conservative value of $0.2 \%$ strain is unjustified. The carried out research also showed a significant reserve in structure's load bearing capacity between ULS according to EN 1993-1-4 [5] and failure. In the case of a type A bracket being analyzed, failure took place at the load that exceeded by three times the ULS limit load causing a $5 \%$ strain.

Depending on the bracket's overhang, the vertical force that meets the typical SLS condition of $3 \mathrm{~mm}$ displacement, can constitute a safe load or a load that causes strain above the $5 \%$ limits. It depends on the rigidity of the designed bracket, and especially on the ratio of the bracket's overhang to its height.

The carried out analysis proved that using a traditional bilinear diagram without strain hardening leads to a significant underestimation of the permissible load due to ULS compared to the tests results or the engineering approach according to CSM (see Table 3, Figs. 16, 17). In practical stainless steel bracket design, it is recommended to use elasto-plastic material model with a stress-strain diagram based on CSM.

\section{Acknowledgement}

This work was partially funded by Project L1/135/2017/P. 


\section{References}

[1] CEN "EN 1991-1-1 Eurocode 1: Actions on structures - Part 1-1: General actions - Densities, self-weight, imposed loads for buildings", European Committee for Standardization, Brussels, Belgium, 2002.

[2] ISO "ISO 7892:1988 Vertical building elements - Impact resistance tests - Impact bodies and general test procedures", International Organization for Standardization, Geneva, Switzerland, 1988.

[3] Baird, A., Palermo, A., Pampanin, S., Riccio, P., Tasligedik, A. S. "Focusing on reducing the earthquake damage to facade systems", Bulletin of the New Zealand Society for Earthquake Engineering, 44(2), pp. 108-120, 2011.

https://doi.org/10.5459/bnzsee.44.2.108-120

[4] EOTA "ETAG 034 Guideline for European technical approval of kits for external wall claddings. Part II: Cladding kits comprising cladding components, associated fixings, subframe and possible insulation layer", European Organisation for Technical Approvals, Brussels, Belgium, 2012.

[5] CEN "EN 1993-1-4:2006 Eurocode 3: Design of steel structures Part 1-4: General rules - Supplementary rules for stainless steels", European Committee for Standardization, Brussels, Belgium, 2006.

[6] Gardner, L. "The continuous strength method", Proceedings of the Institution of Civil Engineers - Structures and Buildings, 161(3), pp. 127-133, 2008.

https://doi.org/10.1680/stbu.2008.161.3.127

[7] Afshan, S., Gardner, L. "The continuous strength method for structural stainless steel design", Thin-Walled Structures, 68, pp. 42-49, 2013.

https://doi.org/10.1016/j.tws.2013.02.011
[8] Nowak, K., Byrdy, A. "Effect of mounting brackets on thermal performance of buildings with ventilated facades", Journal of Building Physics, 43(1), pp. 46-56, 2019. https://doi.org/10.1177/1744259118790759

[9] Bikas, D., Tsikaloudaki, K., Kontoleon, K. J., Giarma, C., Tsoka, S., Tsirigoti, D. "Ventilated Facades: Requirements and Specifications Across Europe", Procedia Environmental Sciences, 38, pp. 148$154,2017$. https://doi.org/10.1016/j.proenv.2017.03.096

[10] CEN "EN 1993-1-1:2005 Eurocode 3: Design of steel structures - Part 1-1: General rules and rules for buildings", European Committee for Standardization, Brussels, Belgium, 2005.

[11] CEN "EN 1990:2002 Eurocode - Basis of structural design", European Committee for Standardization, Brussels, Belgium, 2002.

[12] Dlubal Software "RFEM 5 Spatial Models Calculated According to Finite Element Method, User Manual", Dlubal Software, Tiefenbach, Germany, 2019. [online] Available at: https://www.dlubal.com/en/ downloads-and-information/documents/manuals

[13] Nordberg, H. "Note on the sensitivity of stainless steels to strain rate", AvestaPolarit Research Foundation, London, UK, Rep. 04.0-1, 2004.

[14] Mutz, A. "Strain Limits within the Scope of the Integrity Assessment of Piping Systems", presented at Proceedings of the International Youth Nuclear Congress (IYNC 2008), Interlaken, Switzerland, Sept. 20-26, 2008. 